\title{
Similaridade da qualidade das águas superficiais da bacia do Curu, Ceará
}

\author{
Similarity of surface water quality at Curu watershed, Ceará, Brazil
}

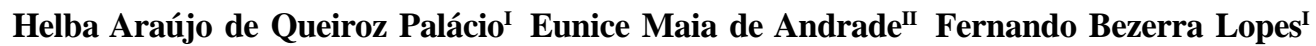 \\ Deborah Mithya Barros Alexandre ${ }^{I}$ Francisco Dirceu Duarte Arraes ${ }^{I}$
}

\section{RESUMO}

Com a demanda de água crescendo a cada ano, é necessária uma maior atenção aos fatores responsáveis da qualidade das águas. Esta pesquisa teve como objetivo identificar a similaridade de variáveis determinantes da qualidade das águas do trecho perenizado da bacia do Curu, Ceará, durante a estação seca e chuvosa, pelo emprego de análise multivariada. As amostras de água foram coletadas em sete pontos (georreferenciados), nos meses de janeiro, março, maio e agosto de 2005, totalizando 28 amostras. Nas águas, foram analisados os seguintes atributos: $\mathrm{pH}, \mathrm{CE}, \mathrm{Ca}^{2+}$, $\mathrm{Mg}^{2+}, \mathrm{Na}^{+}, \mathrm{K}^{+}, \mathrm{Cl}^{-} \mathrm{CO}_{3}^{-}, \mathrm{HCO}_{3}^{-}, \mathrm{SO}_{4}^{-}, \mathrm{PO}_{4}^{3-}, \mathrm{NH}_{4}^{-}$e $\mathrm{NO}_{3}^{-}$. Quatro grupos homogêneos foram identificados, sendo estes independentes da posição geográfica dos pontos de coleta, demonstrando a maior influência da sazonalidade na definição da similaridade da qualidade dessas águas. Os valores da RAS (Razão de Adsorção de Sódio) definiram a dissimilaridade do grupo 1 em relação aos demais; já o grupo 2 foi definido pelo nitrato e fósforo; enquanto que os valores da Condutividade Elétrica (CE) e da RAS, os íons sódio e o cloreto determinaram a dissimilaridade entre os grupos 3 e 4. Embora as águas dessa área sejam inadequadas ao consumo humano, $C E>0,5 d \mathrm{Sm}^{-1}$, o cloreto e o sódio não representam riscos à saúde humana. Com relação aos parâmetros determinantes para irrigação, em apenas um grupo a salinidade apresentou restrição ligeira a moderada, enquanto a RAS apresentou a mesma restrição em todos os grupos.

Palavras-chave: qualidade de água, sazonalidade, análise de agrupamento, análise multivariada.

\section{ABSTRACT}

A special attention should be devoted to the water quality determinant factors, since the water supply has been decreased each year. The aim of this research was to define the similarity of determinant variables of water quality in the perennialized part of the Curu watershed, Ceará, Brazil. Multivariate analysis/Cluster Analysis was used for this investigation and it was proceeded during the wet and dry season. The samples were took in seven stations, spreading out along the rivers during four campaigns of collection (January, March, May and August of 2005), totalizing 28 samples. The water attributes analyzed were: $\mathrm{pH}, \mathrm{Ce}, \mathrm{Ca}^{2+}, \mathrm{Mg}^{2+}, \mathrm{Na}^{+}, \mathrm{K}^{+}, \mathrm{Cl}$, $\mathrm{CO}_{3}^{-}, \mathrm{HCO}_{3}^{-}, \mathrm{SO}_{4}^{-}, \mathrm{PO}_{4}^{3-}, \mathrm{NH}_{4}^{-}$and $\mathrm{NO}_{3}^{-}$. Four homogeneous groups were identified. They were independent of their geographic position. They were identified expressing the influence of weather seasonality. The values of Sodium Adsorption Ratio (RAS) defined the dissimilarity of group 1 in relation to the others. The values of nitrate and phosphorus defined the similarity of group 2; while the Electric Conductivity (CE), RAS, sodium and chloride ions determined the non homogeneity between groups 3 and 4. Although the salinity level of water $\left(C E>0,5 \mathrm{~d} \mathrm{Sm}^{-1}\right)$ was not suitable to human consume, the $\mathrm{Na}^{+}$and $\mathrm{Cl}^{-}$concentration do not present risks to human health. In relation to irrigation, only one group presented salinity risk from low to moderate, while SAR showed the same risk level for all groups.

Key words: water quality, sazonality, cluster analysis, multivariate analysis.

\section{INTRODUÇÃO}

Devido ao crescimento da população mundial, às altas taxas de consumo de água, ao modelo de desenvolvimento adotado e à contaminação dos recursos hídricos pela ação antrópica, a disponibilidade hídrica torna-se cada vez mais escassa (VEGA et al.,

'Programa de Pós-graduação em Engenharia Agrícola, Departamento de Engenharia Agrícola, Universidade Federal do Ceará (UFC), Fortaleza, CE, Brasil.

"Departamento de Engenharia Agrícola, UFC. Av. Mister Hull, s/n, Bloco 804, CP 12168, 60455-970, Fortaleza, CE, Brasil. Email: eandrade@ufc.br. Autor para correspondência. 
1998; ANDRADE et al., 2009). A água é um recurso determinante da qualidade de vida do ser humano. Nas regiões áridas e semiáridas do globo, essa limitação se torna bem mais evidente, como decorrência natural da escassez hídrica da região. A multiplicidade de usos da água conduz a problemas, tanto em termos de quantidade, como de qualidade.

A circulação e distribuição das substâncias químicas no sistema aquático são bem definidas; entretanto, essa dinâmica é influenciada pelas variações climáticas. Em períodos de intensas chuvas, ocorrem nítidas alterações nas concentrações dessas substâncias dissolvidas nas amostras das águas de rio e de reservatório; esse fato é atribuído a descargas de águas salinizadas provenientes dos pequenos reservatórios existentes em toda área drenada (SILVA JÚNIOR et. al., 1999; ANDRADE et al., 2005; SANTOS \& SANTOS, 2008)

A necessidade de um controle mais eficiente na qualidade desse recurso impulsionou a criação de agências e órgãos reguladores, bem como o desenvolvimento de pesquisas para assessorar as atividades de controle e manejo. No campo de manejo de água, cientistas, engenheiros e administradores podem se deparar com uma grande quantidade de dados. Com um número muito grande de variáveis, o número de relações entre elas é, também, muito grande para ser compreendido, e uma técnica que possa resumir essa grande correlação torna-se necessária (DILLON \& GOLDSTEIN, 1984). O tratamento multivariado de dados é muito utilizado para caracterizar e avaliar as águas superficiais e a qualidade das águas doces, sendo útil para evidenciar variações espaciais e temporais causadas por fatores naturais e antropogênicos vinculados à sazonalidade (VEGA et al., 1998).

A análise de agrupamento é um termo usado para descrever diversas técnicas numéricas que classificam uma matriz de dados sob estudo em grupos discretos (BUFON \& LANDIM, 2007). Essa técnica considera um conjunto inicial de objetos aos quais são associadas medidas de várias grandezas, denominadas variáveis classificatórias, que são utilizadas para definir grupos de objetos similares. Ela tem se mostrado bastante eficiente com relação às importantes questões de identificação e responsabilização de fontes poluidoras (MUÑOZ-CARPENA et. al., 2002; SINGH et al., 2004). A partir dessas considerações, aplicou-se a técnica de estatística multivariada com o objetivo de identificar a similaridade de variáveis determinantes da qualidade das águas no trecho perenizado dos cursos hídricos, na bacia do Curu, durante os períodos seco e chuvoso.

\section{MATERIAL E MÉTODOS}

O trabalho foi desenvolvido na bacia hidrográfica do rio Curu, na porção noroeste do Estado do Ceará (Figura 1). Ela detém uma área de $8.605 \mathrm{~km}^{2}$ entre as coordenadas $3^{\circ} 20^{\prime}$ e $4^{\circ} 36^{\prime}$ de latitude Sul e 3855’ e 3950' de longitude Oeste, abrangendo 15 municípios com uma população de 353.345 habitantes. O rio Curu nasce na serra do Machado e deságua no litoral oeste do Ceará, com uma extensão de 195km, sendo perenizado pelos açudes General Sampaio $\left(4.571 .000 \mathrm{~m}^{3}\right)$, Pereira de Miranda $\left(395.600 .000 \mathrm{~m}^{3}\right)$ e Caxitoré (220.000.000m³). Nessa área, encontram-se localizados os perímetros irrigados Curu-Recuperação e Curu Paraipaba (FROTA JÚNIOR et al., 2007).

O clima da parte baixa da bacia é classificado como Aw' - quente e úmido, com chuvas de outono, temperatura média anual superior a $18^{\circ} \mathrm{C}$, precipitação anual média de $1.020 \mathrm{~mm}$ e período seco de julho a dezembro. Já os terços médio e superior da bacia do Curu apresentam clima do tipo BSh’w’, semiárido quente, com chuvas de outono, temperaturas médias sempre superiores a $18^{\circ} \mathrm{C}$. Os solos predominantes na bacia do Curu são os Argissolos, Planossolos, Luvissolos Crômicos ou Háplicos, Neossolos Flúvicos, Quartzarênicos e Regolíticos.

A escolha dos pontos de amostra de água no trecho perenizado da bacia se fundamentou na representatividade do uso da terra, de forma que fosse identificada ou não a ação antrópica na qualidade das águas. No total, foram selecionados sete pontos de amostragem (Figura 1). As atividades predominantes na região, de acordo com a GORAYEB (2004), são: as culturas de subsistência (cultivo de milho e feijão) e fruticultura irrigada, de modo mais expressivo, e os cultivos de cana-de-açúcar e de coco. Para avaliar o impacto de atividades antrópicas e dos fatores naturais sobre a qualidade da água na bacia do Curu, foram realizadas coletas de água, durante os meses de janeiro, março, maio e agosto de 2005, nos sete pontos de amostragem, perfazendo um total de 28 amostras. Foram analisados os parâmetros $\mathrm{pH}$, Condutividade elétrica (CE), $\mathrm{Ca}^{2+}, \mathrm{Mg}^{2+}, \mathrm{Na}^{+}, \mathrm{K}^{+}, \mathrm{HCO}_{3}^{-}, \mathrm{PO}_{4}^{-2}, \mathrm{Cl}^{-}, \mathrm{NH}_{4}^{+}, \mathrm{NO}_{3}^{-}$, $\mathrm{SO}_{4}^{-2}$, Relação de Adsorção de sódio (RAS), OD, DBO, Sólidos Dissolvidos (SD). As análises foram realizadas no Centro Federal de Educação Tecnológica (CEFET), seguindo a metodologia apresentada por APHA (1998).

Com o objetivo de classificar as amostras de água em grupos semelhantes que expressassem respostas hidroquímicas com tendências similares, utilizou-se a análise de agrupamento pelo método aglomerativo via processamento no software SPSS 16.0. Para evitar os erros devido às escalas e unidades das variáveis selecionadas, fez-se a normalização dos dados (média igual a zero e desvio padrão igual a um), 


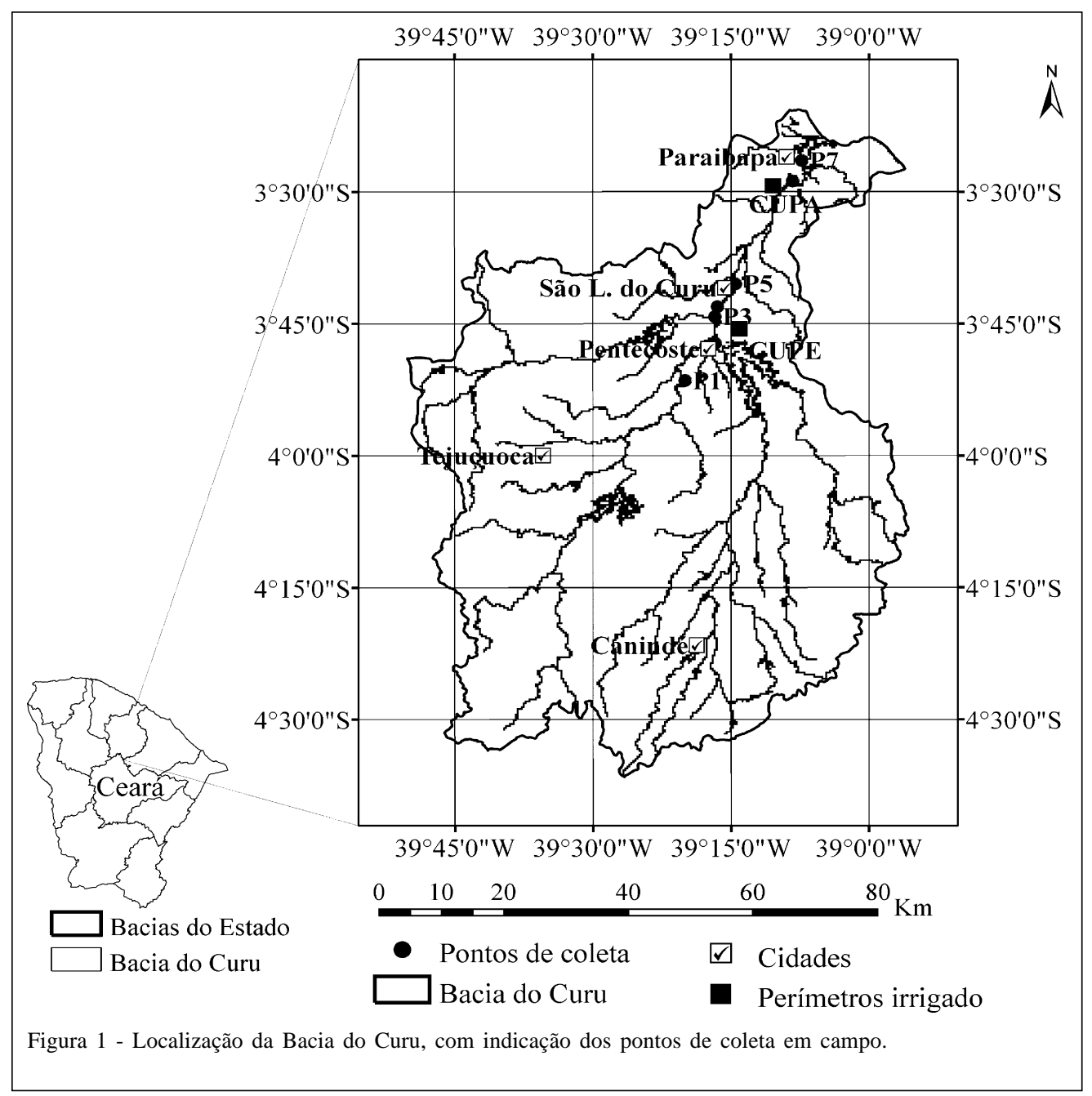

e a similaridade foi estimada por meio da distância Euclidiana ao quadrado. $\mathrm{O}$ algoritmo de agrupamento que foi utilizado na definição dos agregados neste trabalho foi o método Ward. Na definição de um número ótimo de agrupamentos, empregou-se "o coeficiente de aglomeração” (CA), calculado pela equação 1, partindo-se do princípio que aumentos repentinos no valor do coeficiente de aglomeração representam fusão de elementos diferentes, no dendrograma esses aumentos são representados pelos maiores valores da distância reescalonada de combinação de agregados (DILLON \& GOLDSTEIN, 1984). Os dados médios de cada parâmetro analisado dos respectivos grupos formados foram submetidos à análise de teste de média e confrontados pelo teste $\mathrm{t}$, a $1 \%$ de probabilidade de erro, por meio do programa SPSS 16.0 for Windows.

$$
\mathrm{CA}=\sum_{\mathrm{j}=1}^{\mathrm{k}}\left(\sum_{\mathrm{i}=1}^{\mathrm{n}_{\mathrm{j}}} \mathrm{X}_{\mathrm{ij}}^{2}-\frac{1}{\mathrm{n}_{\mathrm{j}}}\left(\sum_{\mathrm{i}=1}^{\mathrm{n}_{\mathrm{j}}} \mathrm{X}_{\mathrm{ij}}\right)^{2}\right)
$$

em que CA: coeficiente de aglomeração; $\mathrm{X}_{\mathrm{ij}}$ : valor da amostra $\mathrm{i}$ individual em cada grupo $\mathrm{j}$; $\mathrm{k}$ : total de amostras em cada estágio; $n_{j}$ : número de amostras do grupo.

\section{RESULTADOS E DISCUSSÃO}

A semelhança das águas entre os pontos de coleta do trecho perenizado da bacia do Curu no período monitorado, avaliada pelo emprego da técnica de análise multivariada, de agrupamento, formou quatro grupos homogêneos (Figura 2). Para definir o número de grupos, tomou-se como base a primeira grande diferença entre os coeficientes de aglomeração de dois grupos consecutivos 41,118 (257,514-216,396). No dendrograma (Figura 2), que corresponde à figura com os coeficientes de aglomeração reescalonados em que o menor coeficiente corresponde a 1 e o maior a 25 , fica explícito que o ponto ótimo de corte é a distância de

Ciência Rural, v.39, n.9, dez, 2009. 


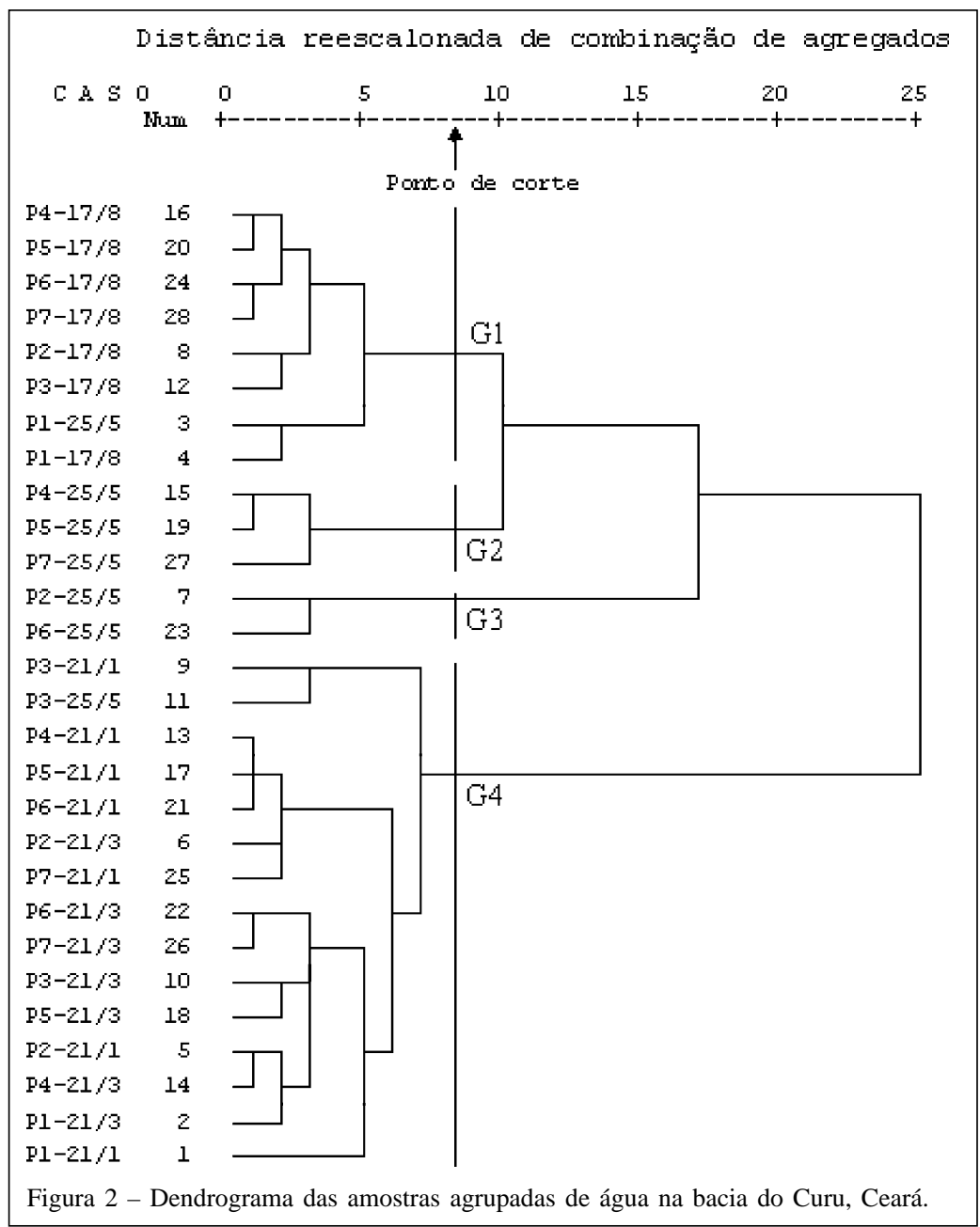

valor logo acima de 6,85, após a formação dos quatro grupos, ponto que corresponde à primeira grande diferença entre dois coeficientes consecutivos 41,118.

O grupo 1 foi formado por águas da estação seca de todos os pontos de coleta, incluindo a coleta do ponto 1 no mês de maio. $O$ grupo 2 foi constituído por águas coletadas no mês de maio, nos pontos 4,5 e 7. O grupo 3 foi composto pelas águas coletadas no mês de maio, nos pontos 2 e 6 . Já o grupo 4 foi formado pelas águas coletadas na estação chuvosa, em todos os pontos, inserindo também a coleta de maio no ponto 3. Observa-se que os grupos foram constituídos principalmente pelas mesmas datas de coleta. Assim, pode-se afirmar que a sazonalidade teve um maior peso na definição da similaridade da qualidade das águas do que a variação espacial. SINGH et al. (2004), monitorando oito pontos para avaliar a variação temporal/espacial da qualidade das águas do rio Gomti no norte da Índia, verificaram que os pontos de coleta poderiam ser reduzidos para três.
O atributo determinante do grupo 1 foi a RAS, a qual diferiu dos demais grupos, (Tabela 1). Esse grupo foi formado pelas amostras da época seca de todos os pontos amostrados, demonstrando a concentração dos sais ao longo do tempo. Não se pode avaliar melhor o nível de concentração ocorrida nessa área, por não se dispor de dados do período mais seco, outubro a dezembro. Na amostra do mês de maio do ponto 1 , as concentrações dos sais dependentes da geologia local foram as que o aproximaram do grupo 1 , indicando que a interferência agrícola na área não é tão intensa, caracterizando-se como um grupo. As águas desse grupo apresentaram maior teor de sais que as demais amostras devido ao efeito da concentração dos sais causado pela evaporação das águas dos reservatórios, que perenizam o trecho no período mais seco. Esse fenômeno é comum nas regiões semiáridas onde o déficit hídrico no período seco chega a 858mm.

O grupo 2 foi composto por águas que apresentaram os maiores valores de nitrato e fosfato, 
Similaridade da qualidade das águas superficiais da bacia do Curu, Ceará.

Tabela 1 - Média e desvio padrão, valores máximo e mínimo das variáveis em estudo para os grupos das águas superficiais da bacia do Curu, Ceará, definidos pela técnica da análise de agrupamento.

\begin{tabular}{|c|c|c|c|c|c|}
\hline Variáveis & Estatísticas & Grupo 1 & Grupo 2 & Grupo 3 & Grupo 4 \\
\hline \multirow{3}{*}{$\mathrm{pH}$} & Média & $7,27 \pm 0,30 a^{1}$ & $7,43 \pm 0,21 \mathrm{a}$ & $7,45 \pm 0,21 \mathrm{a}$ & $7,66 \pm 0,25 b$ \\
\hline & Mínimo & 6,60 & 7,20 & 7,30 & 7,40 \\
\hline & Máximo & 7,50 & 7,60 & 7,60 & 8,40 \\
\hline \multirow{3}{*}{$\mathrm{CE}\left(\mathrm{dS} \mathrm{m}^{-1}\right)$} & Média & $0,61 \pm 0,07 \mathrm{~b}$ & $0,60 \pm 0,03 \mathrm{ba} \mathrm{ba}$ & $1,01 \pm 0,06 \mathrm{c}$ & $0,51 \pm 0,08 \mathrm{a}$ \\
\hline & Mínimo & 0,49 & 0,56 & 0,97 & 0,36 \\
\hline & Máximo & 0,73 & 0,62 & 1,05 & 0,65 \\
\hline \multirow{3}{*}{ RAS } & Média & $2,50 \pm 0,45 b$ & $3,25 \pm 0,24 \mathrm{c}$ & $3,47 \pm 0,56 c$ & $1,70 \pm 0,35 \mathrm{a}$ \\
\hline & Mínimo & 1,87 & 3,00 & 3,08 & 1,16 \\
\hline & Máximo & 3,41 & 3,49 & 3,87 & 2,33 \\
\hline \multirow{3}{*}{$\mathrm{Ca}^{2+}\left(\mathrm{mmol}_{\mathrm{c}} \mathrm{L}^{-1}\right)$} & Média & $1,27 \pm 0,33 \mathrm{~b}$ & $1,27 \pm 0,23 \mathrm{~b}$ & $1,70 \pm 0,28 b c$ bc & $1,17 \pm 0,21$ ba ba \\
\hline & Mínimo & 0,80 & 1,00 & 1,50 & 0,90 \\
\hline & Máximo & 1,80 & 1,40 & 1,90 & 1,60 \\
\hline \multirow{3}{*}{$\mathrm{Mg}^{2+}\left(\mathrm{mmol}_{\mathrm{c}} \mathrm{L}^{-1}\right)$} & Média & $1,74 \pm 0,38 \mathrm{a}$ & $1,13 \pm 0,21 \mathrm{a}$ & $2,80 \pm 0,42 b$ & $1,76 \pm 0,47 a b$ \\
\hline & Mínimo & 0,90 & 0,90 & 2,50 & 0,60 \\
\hline & Máximo & 2,10 & 1,30 & 3,10 & 2,30 \\
\hline \multirow{3}{*}{$\mathrm{Na}^{+}\left(\mathrm{mmol}_{\mathrm{c}} \mathrm{L}^{-1}\right)$} & Média & $3,05 \pm 0,59 b$ & $3,53 \pm 0,29 b$ & $5,20 \pm 0,42 \mathrm{c}$ & $2,03 \pm 0,42 \mathrm{a}$ \\
\hline & Mínimo & 2,30 & 3,20 & 4,90 & 1,40 \\
\hline & Máximo & 4,20 & 3,70 & 5,50 & 3,00 \\
\hline \multirow{3}{*}{$\mathrm{K}^{+}\left(\mathrm{mmol}_{\mathrm{c}} \mathrm{L}^{-1}\right)$} & Média & $0,21 \pm 0,03 \mathrm{~b}$ & $0,27 \pm 0,06 \mathrm{bc}$ bc & $0,25 \pm 0,07 b$ & $0,16 \pm 0,05 b a$ ba \\
\hline & Mínimo & 0,20 & 0,20 & 0,20 & 0,10 \\
\hline & Máximo & 0,30 & 0,30 & 0,30 & 0,20 \\
\hline \multirow{3}{*}{$\mathrm{Cl}^{-}\left(\mathrm{mmol}_{\mathrm{c}} \mathrm{L}^{-1}\right)$} & Média & $4,05 \pm 0,66 \mathrm{~b}$ & $4,33 \pm 0,76 b$ & $8,15 \pm 0,21 \mathrm{c}$ & $3,20 \pm 0,52 \mathrm{a}$ \\
\hline & Mínimo & 3,00 & 3,80 & 8,00 & 2,20 \\
\hline & Máximo & 5,20 & 5,20 & 8,30 & 4,40 \\
\hline \multirow{3}{*}{$\mathrm{HCO}_{3}\left(\mathrm{mmol}_{\mathrm{c}} \mathrm{L}^{-1}\right)$} & Média & $2,16 \pm 0,07 \mathrm{a}$ & $1,70 \pm 0,66 \mathrm{a}$ & $1,90 \pm 0,71 \mathrm{a}$ & $1,95 \pm 0,26 \mathrm{a}$ \\
\hline & Mínimo & 0,49 & 1,00 & 1,40 & 1,40 \\
\hline & Máximo & 0,73 & 2,30 & 2,40 & 2,20 \\
\hline \multirow{3}{*}{$\mathrm{SO}_{4}^{-}\left(\mathrm{mmol}_{\mathrm{c}} \mathrm{L}^{-1}\right)$} & Média & $4,78 \pm 4,01 \mathrm{a}$ & $9,48 \pm 1,39$ a & $9,33 \pm 3,41 \mathrm{a}$ & $7,60 \pm 4,16 \mathrm{a}$ \\
\hline & Mínimo & 0,64 & 8,40 & 6,92 & 0,25 \\
\hline & Máximo & 10,75 & 11,05 & 11,64 & 14,35 \\
\hline \multirow{3}{*}{$\mathrm{PO}_{4}^{3-}\left(\mathrm{mg} \mathrm{L}^{-1}\right)$} & Média & $0,04 \pm 0,03 \mathrm{a}$ & $0,32 \pm 0,09 \mathrm{c}$ & $0,12 \pm 0,03 \mathrm{ab} a b$ & $0,12 \pm 0,07 \mathrm{~b}$ \\
\hline & Mínimo & 0,01 & 0,22 & 0,10 & 0,04 \\
\hline & Máximo & 0,12 & 0,41 & 0,14 & 0,27 \\
\hline \multirow{3}{*}{$\mathrm{NH}_{4}^{-}\left(\mathrm{mg} \mathrm{L}^{-1}\right)$} & Média & $0,19 \pm 0,14 \mathrm{a}$ & $0,59 \pm 0,07 a b$ & $0,47 \pm 0,05 a b a b$ & $3,20 \pm 3,22 b$ \\
\hline & Mínimo & 0,05 & 0,51 & 0,43 & 0,22 \\
\hline & Máximo & 0,50 & 0,64 & 0,50 & 7,47 \\
\hline \multirow{3}{*}{$\mathrm{NO}_{3}^{-}\left(\mathrm{mg} \mathrm{L}^{-1}\right)$} & Média & $0,30 \pm 0,18 \mathrm{a}$ & $0,58 \pm 0,13 b$ & $0,26 \pm 0,13 \mathrm{a}$ & $036 \pm 0,25 \mathrm{a}$ \\
\hline & Mínimo & 0,10 & 0,49 & 0,18 & 0,09 \\
\hline & Máximo & 0,56 & 0,73 & 0,35 & 0,94 \\
\hline \multirow{3}{*}{ S. D. $\left(\mathrm{mg} \mathrm{L}^{-1}\right)$} & Média & $607 \pm 72 b$ & $600 \pm 35 a b$ & $1010 \pm 57 \mathrm{c}$ & $511 \pm 77 \mathrm{a}$ \\
\hline & Mínimo & 490 & 560 & 970 & 360 \\
\hline & Máximo & 730 & 620 & 1050 & 650 \\
\hline \multirow{3}{*}{$\mathrm{OD}\left(\mathrm{mg} \mathrm{L}^{-1}\right)$} & Média & $3,12 \pm 1,07 \mathrm{a}$ & $4,57 \pm 0,15 \mathrm{a}$ & $5,24 \pm 0,31 \mathrm{a}$ & $5,46 \pm 1,08 b$ \\
\hline & Mínimo & 1,53 & 4,41 & 5,02 & 4,00 \\
\hline & Máximo & 4,38 & 4,72 & 5,46 & 8,50 \\
\hline \multirow{3}{*}{ DBO (mg L $\left.{ }^{-1}\right)$} & Média & $4,88 \pm 1,09 \mathrm{~b}$ & $3,11 \pm 0,84 a b a b$ & $2,22 \pm 0,93 \mathrm{a}$ & $2,03 \pm 1,17 \mathrm{a}$ \\
\hline & Mínimo & 2,45 & 2,51 & 1,57 & 0,56 \\
\hline & Máximo & 5,76 & 4,07 & 2,88 & 3,76 \\
\hline
\end{tabular}

1: médias não seguidas por mesma letra, entre grupos dentro de cada variável, diferem pelo teste t, a $1 \%$ de probabilidade de erro. 
indicando que nessa época a ação antrópica é determinante para a qualidade da água na área, tendo em vista que esse grupo foi formado pelas amostras de água coletadas no mês que corresponde ao período de ocorrência das maiores chuvas e, consequentemente, promoveram a lavagem e o carreamento dos nutrientes para os corpos hídricos nos pontos 4, 5, 7. Acredita-se que a fonte dos nutrientes presentes no solo dessa região seja os fertilizantes utilizados na agricultura irrigada dos perímetros Curu Pentecoste e os efluentes de esgotos das cidades de São Luis do Curu e Paraipaba, que ficam localizados a montante dos pontos de coleta. MUÑOZ-CARPENA et al. (2002), estudando a degradação do aquífero em uma área fertirrigada de banana nas Ilhas Canary, Espanha, constataram um incremento na concentração de nitrato no aquífero da área, nos períodos de chuva e de maior demanda evaporativa da cultura.

Os atributos determinantes do grupo 3 foram $\mathrm{Cl}^{-}, \mathrm{Na}^{+}$, CE e Sólidos dissolvidos, que diferiram estatisticamente ao nível de $1 \%$ dos demais grupos (Tabela 1). Ele apresentou as maiores médias para CE, RAS, $\mathrm{Ca}^{2+}, \mathrm{Mg}^{2+}$ em relação a todos os outros grupos. Esse fato evidencia que o teor de salinidade presente na área é mais elevado e que as chuvas anteriores não haviam sido suficientes para promover uma intensa lavagem dos solos. Quando ocorreram as maiores chuvas, a lavagem do solo foi realizada carreando os nutrientes para o rio. $\mathrm{O}$ grupo 3 apresentou qualidade de água inferior aos demais, e esse fato pode ser explicado pela localização do ponto 2 nas proximidades e a jusante da cidade de Pentecoste. A referida cidade, com uma população de 33.717 habitantes (IBGE, 2007), não possui sistema de tratamento de esgoto, tendo seus dejetos depositados em fossas rudimentares e o lixo colocado em amontoados a céu aberto. Também contribui para que o grupo 3 tenha esse status o fato de o ponto 2 representar águas que drenam solos classificados como luvissolos, os quais podem colaborar para a composição química das águas com os elementos $\mathrm{Ca}^{2+}, \mathrm{Mg}^{2+}$ e $\mathrm{Na}^{+}$(FROTA JÚNIOR et. al., 2007). SILVA JÚNIOR et. al. (1999) destaca que a qualidade das águas superficiais, no Nordeste brasileiro (composição química e, sobretudo, nível de concentração), está claramente relacionada com a natureza do substrato local, especificamente a natureza da rocha e o tipo de solo.

A pior qualidade das águas no ponto 6 pode ser explicada pelo uso da terra. A drenagem e lavagem dos solos do perímetro irrigado Curu Paraipaba, que fica logo a montante do ponto de coleta, causam a contaminação localizada. Esse perímetro tem como sua principal cultura o coco, que emprega vários adubos, dentre eles, os que usam o $\mathrm{KCl}$ como suprimento de potássio.

Os atributos determinantes do grupo 4 foram os baixos valores do $\mathrm{Na}^{+}, \mathrm{Cl}^{-}$, RAS, pH e OD, caracterizando a diluição dos sais ocorrida na estação chuvosa e diferindo estaticamente dos demais grupos (Tabela 1). Esse comportamento de diluição dos sais no período chuvoso é comum nas regiões semiáridas, pois as águas das chuvas possuem uma concentração salina de CE 0,05d Sm${ }^{-1}$. Os principais elementos responsáveis por essa tendência na região semiárida são os $\mathrm{Na}^{+}, \mathrm{Cl}^{-}$(SILVA JÚNIOR et al., 1999). Comportamento semelhante de diluição de sais no período chuvoso foram encontrados por ANDRADE et al. (2005).

Comparando esse grupo com o grupo 1, pode-se notar que eles diferiram estatisticamente nos elementos CE, RAS, $\mathrm{Na}^{+}$, $\mathrm{Cl}^{-}$, SD e DBO, que foram inferiores no grupo 4, confirmando mais uma vez que as chuvas provocam a diluição dos sais. Os parâmetros $\mathrm{PO}_{4}{ }^{3}, \mathrm{NH}_{4}^{+}$, OD e $\mathrm{pH}$, que foram superiores no grupo 4, indicam que as chuvas promovem a lavagem dos solos e carreiam para os corpos hídricos o material orgânico oriundo dos excrementos dos animais, os restos vegetais presentes na área e os nutrientes, aumentando o teor desses parâmetros no período chuvoso (TOLEDO \& NICOLELLA, 2002). Outro dado importante ao comparar esses dois grupos é que os indicadores de contaminação causada por ação antrópica, como $\mathrm{NO}_{3}{ }_{3}^{-}, \mathrm{NH}_{4}^{+}, \mathrm{PO}_{4}^{3-}$ e $\mathrm{SO}_{4}^{-}$, são maiores no grupo 4, que corresponde ao período chuvoso, época em que a chuva, ao promover a lavagem dos solos, carreia para os corpos hídricos os elementos provenientes da atividade humana. Uma outra possível fonte para esses íons estarem presentes são os adubos aplicados nos perímetros irrigados, que utilizam principalmente uréia, nitrato de potássio, cloreto de potássio e superfosfato como fonte de macro nutrientes para culturas como coco e banana (D’ALMEIDA et al., 2005). Outras fontes desses íons, na região, são os excrementos humanos lançados ao solo por meio de fossas rudimentares. ANDRADE et al. (2009), estudando a qualidades das águas subterrâneas na parte baixa da bacia do Acaraú, encontraram contaminação das águas pela influência das fossas rudimentares. GORAYEB (2004) citou a existência de “lixões” nesse município, em General Sampaio, Tejuçuoca, Itatira e Itapajé, todos localizados sobre ressurgências hídricas ou em trechos de riachos (afluentes dos principais tributários do rio Curu), contribuindo significativamente, por meio da ação antrópica, para o aumento na concentração de sódio. 
Tendo em vista que as coletas do mês de janeiro e março demonstraram o mesmo comportamento, poderia ser realizada apenas uma coleta nesse período, reduzindo o custo do monitoramente. Além disso, como a sazonalidade foi fator determinante na formação dos grupos, sugere-se que, para melhor caracterizar as águas da região, é preciso distribuir melhor as coletas ao longo do ano, fazendo campanhas de amostragem no período mais chuvoso e mais seco do ano.

\section{CONCLUSÕES}

Embora a ação antrópica tenha influenciado a qualidade das águas do trecho perenizado do rio Curu, a definição dos agrupamentos foi determinada principalmente pela concentração e diluição dos íons decorrentes da sazonalidade climática.

\section{REFERÊNCIAS}

ANDRADE, E.M. et al. Impacto da lixiviação de nitrato e cloreto no lençol freático sob condições de cultivo irrigado. Ciência Rural, v.39, n.1, p.88-95, 2009. Disponível em: <http://dx.doi.org/10.1590/S0103-84782009000100014>. Acesso em: 23 abr. 2009. doi: 10.1590/S0103-84782009000100014.

ANDRADE, E.M. et al. Índice de qualidade de água, uma proposta para o vale do rio Trussu, Ceará. Revista Ciência Agronômica, v.36, n.2, p.135-142, 2005. Disponível em: <http://ccarevista.ufc.br/seer/index.php/ccarevista/article/view/ 259/254>. Acesso em: 23 abr. 2009.

APHA. Standard methods for the examination of water and wastewater. 20.ed. Washington, DC: American Public Health Association, 1998. 1220p.

BUFON, A.G.M.; LANDIM, P.M.B. Análise da qualidade da água por metodologia estatística multivariada na represa velha (CEPTA/IBAMA/Pirassununga/SP). Holos Environment, v.7, n.1, p.42-59, 2007. Disponível em: <http://cecemca.rc.unesp.br/ ojs/index.php/holos/article/view/972/903>. Acesso em: 23 abr. 2009.

D’ALMEIDA, D.M.B.A. et al. Importância relativa dos íons na salinidade de um cambissolo na chapada do Apodi, Ceará. Engenharia Agrícola, v.25, n.3, p.615-621, 2005. Disponível em: <http:// dx.doi.org/10.1590/S0100-69162005000300006>. Acesso em: 23 abr. 2009. doi: 10.1590/S0100-69162005000300006.
DILLON, W.R.; GOLDSTEIN, M. Multivariate analysis methodos and applications. New York: John Wiley e Sons, 1984. 587p.

FROTA JÚNIOR, J.I. et al. Influência antrópica na adição de sais no trecho perenizado da bacia hidrográfica do Curu, Ceará. Revista Ciência Agronômica, v.38, n.2, p.142-148, 2007. Disponível em: <http://ccarevista.ufc.br/seer/index.php/ ccarevista/article/viewFile/126/121>. Acesso em: 23 abr. 2009.

GORAYEB, A. Análise geoambiental e dos impactos na Bacia Hidrográfica do Rio Curu - Ceará - Brasil. 2004. 141f. Dissertação (Mestrado em Geografia) - Universidade Estadual do Ceará, Fortaleza-CE.

IBGE - Instituto Brasileiro de Geografia e Estatística. Contagem de população 2007. Disponível em: <www.ibge.gov.br>. Acesso: 04/12/2008.

MUÑOZ-CARPENA, R. et al. Nitrogen evolution and fate in a Canary Islands (Spain) sprinkler fertigated banana plot. Agricultural Water Management, v.52, p.93-117, 2002. Disponível em: $<$ http://dx.doi.org/10.1016/80378-3774(01)00131-7>. Acesso em: 23 abr. 2009. doi: 10.1016/80378-3774(01)00131-7.

SANTOS, J.S.; SANTOS, M.L.P. Estudo da mobilização de metais e elementos traços em ambientes aquáticos do semiárido brasileiro aplicando análise de componentes principais. Química Nova, v.31, n.5, p.1107-111, 2008. Disponível em: <http://dx.doi.org/10.1590/S0100-40422008000500032>. Acesso em: 23 abr. 2009. doi: 10.1590/S010040422008000500032 .

SILVA JÚNIOR, L.G.A. et al. Composição química de águas do cristalino do Nordeste brasileiro. Revista Brasileira de Engenharia Agrícola e Ambiental, v.3, n.1, p.11-17, 1999. Disponível em: < http://www.agriambi.com.br/>. Acesso em: 23 abr. 2009.

SINGH, K.P. et al. Multivariate statistical techniques for the evaluation of spatial and temporal variations in water quality of Gomti River (Índia) - a case study. Water Research, v.38, n.18, p.3980-3992, 2004. Disponível em: <http://dx.doi.org/ 10.1016/j.watres.2004.06.011>. Acesso em: 23 abr. 2009. doi:10.1016/j.watres.2004.06.011.

TOLEDO, L.G.; NICOLELLA, G. Índice de qualidade de água em microbacia sob uso agrícola e urbano. Scientia Agrícola, v.59, n.1, p.181-186, 2002. Disponível em: <http://dx.doi.org/ 10.1590/S0103-90162002000100026>. Acesso em: 23 abr. 2009. doi: 10.1590/S0103-90162002000100026.

VEGA, M. et al. Assessement of seasonal and polluting effects on the quality of river water by exploratory data analysis. Water Research, v.32, n.12, p.3581-3592, 1998. Disponível em: <http://dx.doi.org/10.1016/S0043-1354(98)00138-9>. Acesso em: 23 abr. 2009. doi: 10.1016/S0043-1354(98)00138-9. 